\title{
The application of tree-rings and stable isotopes for reconstructions of climate conditions in the Russian Altai
}

\section{Journal Article}

Author(s):

Sidorova, O.V.; Siegwolf, R.T.W.; Myglan, V.S.; Ovchinnikov, D.V.; Shishov, V.V.; Helle, G.; Loader, N.J.; Saurer, M.

Publication date:

2013-09

Permanent link:

https://doi.org/10.3929/ethz-b-000071089

Rights / license:

In Copyright - Non-Commercial Use Permitted

Originally published in:

Climatic Change 120(1-2), https://doi.org/10.1007/s10584-013-0805-5 


\title{
The application of tree-rings and stable isotopes for reconstructions of climate conditions in the Russian Altai
}

\author{
O. V. Sidorova $\cdot$ R. T. W. Siegwolf • V. S. Myglan • \\ D. V. Ovchinnikov • V. V. Shishov • G. Helle • \\ N. J. Loader • M. Saurer
}

Received: 13 June 2012 / Accepted: 24 May 2013 / Published online: 9 June 2013

(C) Springer Science+Business Media Dordrecht 2013

\begin{abstract}
We present new tree-ring width, $\delta^{13} \mathrm{C}$, and $\delta^{18} \mathrm{O}$ chronologies from the Koksu site $\left(49^{\circ} \mathrm{N}, 86^{\circ} \mathrm{E}, 2,200 \mathrm{~m}\right.$ asl), situated in the Russian Altai. A strong temperature signal is recorded in the tree-ring width (June-July) and stable isotope (July-August) chronologies, a July precipitation signal captured by the stable isotope data. To investigate the nature of common climatic patterns, our new chronologies are compared with previously published tree-ring and stable isotope data from other sites in the Altai region. The temperature signal preserved in the conifer trees is strongly expressed at local and regional scales for all studied sites, resulting in even stronger temperature and precipitation signals in combined average chronologies compared to separate chronologies. This enables the reconstruction of JuneJuly and July-August temperatures for the last 200 years using tree-ring and stable carbon isotopes. A July precipitation reconstruction based on oxygen isotopic variability recorded in tree-rings can potentially improve the understanding of hydrological changes and the occurrence of extreme events in the Russian Altai.
\end{abstract}

Electronic supplementary material The online version of this article (doi:10.1007/s10584-013-0805-5) contains supplementary material, which is available to authorized users.

O. V. Sidorova $(\bowtie) \cdot R$. T. W. Siegwolf $\cdot$ M. Saurer

Paul Scherrer Institute, Villigen, Switzerland 5232

e-mail: olga.sidorova@psi.ch

O. V. Sidorova

e-mail: olga.sidorova@bluewin.ch

V. S. Myglan • V. V. Shishov

Siberian Federal University, Svobodniy 79, Krasnoyarsk, Russia 660049

D. V. Ovchinnikov

V.N. Sukachev Institute of Forest SB RAS, Krasnoyarsk, Russia 660036

G. Helle

Helmholz-Centre Potsdam, German Centre for GeoSciences-GFZ, Telegrafenberg, 14473 Potsdam, Germany

N. J. Loader

Department of Geography, Swansea University, Swansea SA2 8PP, UK 


\section{Introduction}

The Russian Altai is one of the last remaining undisturbed areas of the world comprising an ecological mosaic of coniferous forests, inter-montane steppes, and alpine meadows. Pronounced climate warming observed in this region over recent decades, has resulted in a reduction in the thickness and extent of the Altai glaciers (Eichler et al. 2009). Sidorova et al. (2012) found evidence that tree-ring width (TRW) and stable isotopes of larch (Larix sibirica Ldb.) in the Altai reflected a summer warming trend and indicated thawing of permafrost due to annual temperature increase over the last century. In contrast, a tree-ring stable oxygen isotope study from pine (Pinus sibirica (Du Tour)) growing at the Aktash region of Altai, and in agreement with local instrumental data showed no twentieth-century summer warming trend (Loader et al. 2010). TRW chronologies obtained from across the Russian Altai sampled at the upper tree line, which is believed to be more sensitive to temperature, exhibit increasing radial growth and hence reflect the increase in summer temperatures observed in these areas over the last two centuries (Myglan et al. 2009), while, perhaps surprisingly, tree-ring width chronologies obtained from the sites located closest to the glaciers do not show an increasing growth trend during the recent period (Ovchinnikov et al. 2002). The demonstrated palaeoclimate potential of TRW (Adamenko 1978) and stable isotope chronologies previously established for the Russian Altai exhibit high potential for such a multi-proxy approach (Sidorova et al. 2012).

The application of stable isotope analysis in combination with dendrochronology is increasing as a palaeoecological approach because the ${ }^{13} \mathrm{C} /{ }^{12} \mathrm{C}$ and ${ }^{18} \mathrm{O} /{ }^{16} \mathrm{O}$ in wood/cellulose, provide complementary information about climatic variability from that attainable from TRW or maximum density measurements. The stable carbon isotope ratios of tree-rings reflect the balance between water availability, air humidity and photosynthetic rate, which impact carbon and water cycle relations.

The oxygen isotope ratio is primarily influenced by the isotopic composition of the source water, used by the tree during photosynthesis. The ${ }^{18} \mathrm{O} /{ }^{16} \mathrm{O}$ ratios in treerings contain temperature and precipitation signals that reflect air-mass history and which is subsequently stored in the wood and cellulose of tree-rings (Craig 1961; Dansgaard 1964).

Therefore the carbon and oxygen isotope ratios measured in the same tree-rings are a useful tool for better understanding tree response to both, climate and climate-driven changes in physiological processes. In combination with TRW measurements, it should be possible to distinguish more fully the impact of temperature or water availability (precipitation) and air humidity as the driving climatic parameter. A multi-proxy, multi-site approach is important particularly in topographically complex regions such as the Russian Altai.

In this paper we present new chronologies of TRW, as well as $\delta^{13} \mathrm{C}$ and $\delta^{18} \mathrm{O}$ of cellulose from the Koksu site, located in the Russian Altai with the aims

1. to reveal the response of trees to temperature and precipitation changes during the recent period based on weather station data;

2. to investigate the nature of common climatic patterns by comparing our new chronologies with previously published data from other Altai sites;

3. to construct regional tree-ring width and stable isotope chronologies for the Russian Altai;

4. to reconstruct separate summer temperature and precipitation from a combination of TRW and stable isotopes. 


\section{Material and methods}

\subsection{Study sites}

Fifteen samples from living Larix sibirica $\mathrm{Ldb}$. trees were collected for dendrochronological and stable isotope analyses at the Koksu site (KOK) $\left(49^{\circ} \mathrm{N}, 86^{\circ} \mathrm{E}, 2,200 \mathrm{~m}\right.$ asl) (Fig. 1a).

The KOK site is characterized by an Alpine relief form and vegetation type. The dominant trees are larch. The trees growing at the upper tree line $(2,200-2,400 \mathrm{~m}$ asl), (Fig. 1b) can attain ages in excess of 600-800 years. Four cores were taken from each tree at a height of $1.3 \mathrm{~m}$ with a $0.5 \mathrm{~cm}$ internal diameter increment borer for TRW and stable isotope analyses.

Data from the KOK site were compared with published stable isotope chronologies for Siberian pine (Pinus sibirica (Du Tour)) from Aktash (AKT) $\left(50^{\circ} \mathrm{N}, 87^{\circ} \mathrm{E}, 2,300 \mathrm{~m}\right.$ asl) (Loader et al. 2010), which is located $47 \mathrm{~km}$ west of the KOK, and Mongun (MOG), a site with Siberian larch (Larix sibirica (Ldb.)) studied by Sidorova et al. (2012), located close to the treeline at an elevation of about 2,300-2,400 $\mathrm{m}$ asl.

\section{a)}

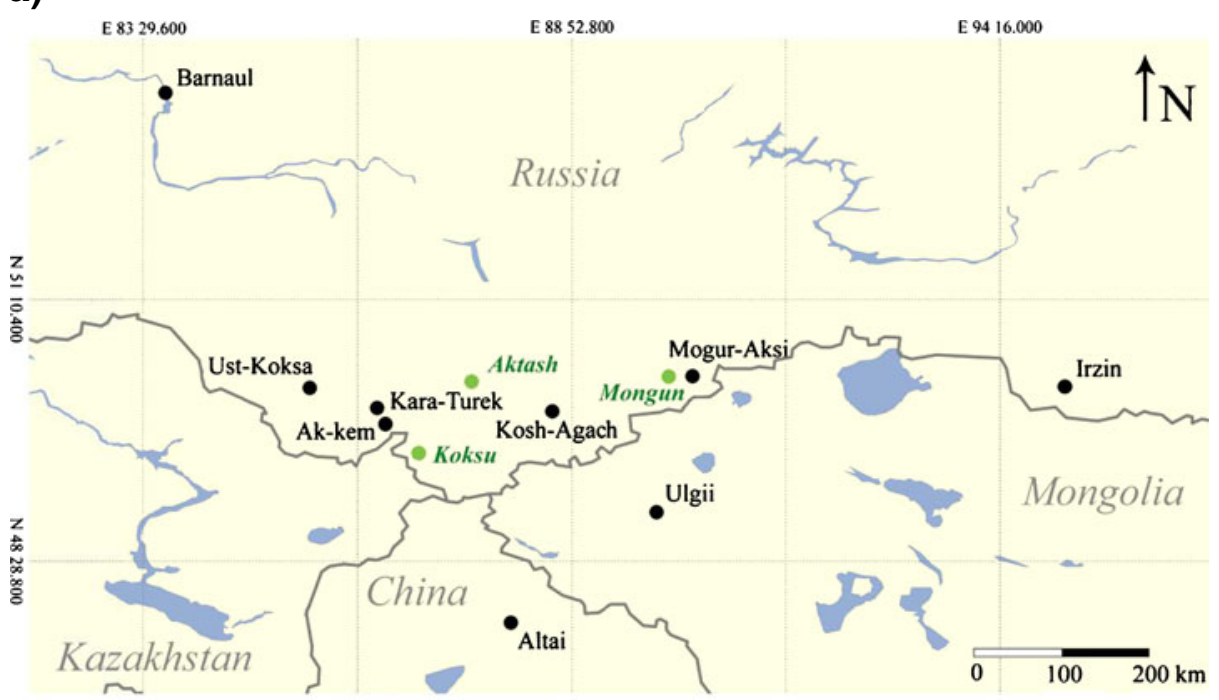

b)

(1)

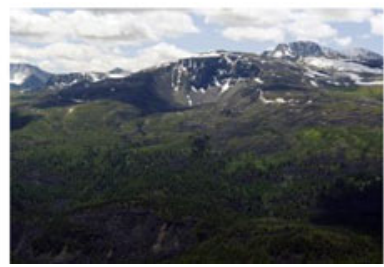

(2)

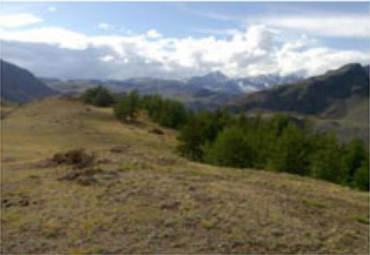

(3)

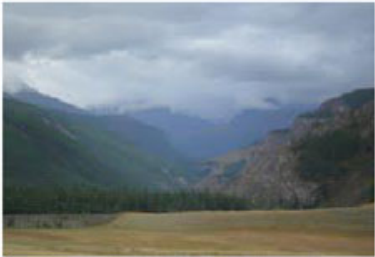

Fig. 1 Map with the locations of the study sites and local weather stations (a). Photos of the study sites (b) 1) Koksu, (KOK), 2) Mongun Taiga (MOG), and 3) Aktash (AKT) 
All three sites (KOK, MOG and AKT) are characterized by a continental climate with short vegetation periods (Adamenko 1978). Annual precipitation for KOK and AKT sites is around $600 \mathrm{~mm}$ compared to the MOG site $(350 \mathrm{~mm})$ according to the geophysical map of distribution of precipitation and air masses http://www-2010.rsu.edu.ru.

While larch trees from the MOG site grow on permafrost, which is characterized by an active layer thawing up to $1 \mathrm{~m}$ deep during the summer time, there is no permafrost at the KOK and AKT sites. All studied sites are located far from industrial centres and could be considered as sites without human impact.

\subsection{Climate data}

Available climate records close to the study site are of limited duration (35 years) and typically contain data gaps $(1934,1958)$. We therefore used monthly temperature and precipitation data for several weather stations from across the wider Russian Altai region (Fig. 1a; Table 3S). The summer temperature trends are similar among the different weather stations and correlate significantly among each other within the range of 0.63-0.91 for the June-July air temperature and of $0.38-0.89$ for the July-August air temperature for the common period 1961-1987. However, the July precipitation records show different patterns with insignificant or low (0.34) correlation coefficients between grid data $\left(0.5^{\circ} \times 0.5^{\circ}\right)$ and data from the local weather stations such as Barnaul, Ak-kem, Uigii, Ust-Koksa and Izrin for the common period 1966-1993, which could be explained by differences in the spatial distribution of precipitation in the mountain areas, as well as differences in elevation of the weather stations.

For these statistical analyses we have selected the weather data from the Chinese Altai station for the KOK and AKT sites, since this is the closest station with long data observations. The Kosh-Agach weather station data was selected for the MOG site. Gridded temperature and precipitation data $\left(0.5^{\circ} \times 0.5^{\circ}\right.$ within the coordinates $45^{\circ} \mathrm{N}-55^{\circ} \mathrm{N}$ and $85^{\circ} \mathrm{E}-95^{\circ} \mathrm{E}$ ) from the Climate Research Unit (CRU version TS 2.1) (Mitchell and Jones 2005) for the period from 1938 to 2000 were used for the common spatial correlation analysis with tree-ring width parameters and $\delta^{13} \mathrm{C}$, and $\delta^{18} \mathrm{O}$ in tree-ring cellulose (http:// climexp.knmi.nl).

\subsection{Dendrochronological analysis}

The ring-widths of cores from fifteen trees from the KOK site were measured using a semiautomatic device (LINTAB V-3.0 Frank Rinn, Germany) with a precision of $0.01 \mathrm{~mm}$ and cross-dated to determine the exact calendar date for each tree-ring (Schweingruber 1996). The tree-ring width chronologies from KOK and compared AKT and MOG sites were standardized according to the standard procedures provided by the ARSTAN program (Cook and Krusic 2008) by selection of a negative exponential curve $(k>0)$ or a linear regression (any slope).

The Expressed Population Signal (EPS) was calculated to define a threshold level of common signal preserved between tree-ring series in year-to-year variations, based on the average correlation between the trees. Normally, an EPS higher than 0.85 is considered the level above which a common signal may be sufficient for robust climate reconstruction (Wigley et al. 1984). 


\subsection{Climate reconstruction}

A palaeoclimatic reconstruction is based on the transfer function (Fritts 1976) model of the relationship between the proxy and the instrumental data, applied to the proxy data for the reconstruction period. In most cases, this involves a simple or multiple linear regression analysis, which is the focus of our study.

To verify an obtained model, the total time span of observations is divided to two independent parts: a calibration (to estimate regression coefficients and statistical quality of the model) and a verification period (to estimate forecast power of the model).

Statistical values such as Pearson's correlation coefficient (r), coefficient of determination $\left(\mathrm{R}^{2}\right)$, Fisher criteria (F-criteria) (Draper and Smith 1966; Cook and Kairiukstis 1990) were calculated.

To estimate the synchronicity between the regression-based reconstruction and original climatic time series and to assess the statistical adequacy of the regression models we calculated the coefficient of synchronicity $\left(\mathrm{K}_{\mathrm{s}}\right)$ (Hettmansperger 1984). To tests first-order autocorrelation in the residuals in a statistical regression analysis the Durbin-Watson statistic (DW) was calculated with low $\left(\mathrm{D}_{\mathrm{L}}\right)$ and upper $\left(\mathrm{D}_{\mathrm{U}}\right)$ critical levels (Durbin and Watson, 1951).

\subsection{Stable isotope analysis}

The ${ }^{13} \mathrm{C} /{ }^{12} \mathrm{C}$ and ${ }^{18} \mathrm{O} /{ }^{16} \mathrm{O}$ isotope ratios were analyzed for five trees separately for the period 1779-2008. Earlier studies have shown that where a strong common inter-annual signal is preserved, as few as four trees may be sufficient to attain this EPS threshold value (McCarroll and Loader 2004; Leavitt 2010). The first 50 years of each sample were excluded to avoid the possible influence of the juvenile effect (McCarroll and Loader 2004; Sidorova et al. 2008; Young et al. 2011).

The whole wood samples were enclosed in a filter bags/extraction tubes and cellulose extraction was performed in $10 \% \mathrm{NaOH}$ and $7 \% \mathrm{NaClO}_{2}$ based upon the method described by Loader et al. (1997).

For each annual ring cellulose was weighed into tin capsules, $0.2-0.3 \mathrm{mg}$ for ${ }^{13} \mathrm{C} /{ }^{12} \mathrm{C}$ and $0.5-0.6 \mathrm{mg}$ into silver capsules for ${ }^{18} \mathrm{O} /{ }^{16} \mathrm{O}$.

The carbon and oxygen isotopic ratio in cellulose was determined using an isotope ratio mass spectrometer Delta-S and a Delta-XP (Finnigan MAT, Bremen, Germany) linked to two elemental analyzers (EA-1110 Carlo Erba and EA-1108, Italy) via a variable open split interface (CONFLO-II, Finnigan MAT, Bremen, Germany).

The isotopic values were expressed in the delta $(\delta)$ notation relative to the international standards:

$$
\delta_{\text {sample }}=\left(\mathrm{R}_{\text {sample }} / \mathrm{R}_{\text {standard }}-1\right) \times 1000 \% \text {, }
$$

where $\mathrm{R}_{\text {sample }}$ is the molar fraction of ${ }^{13} \mathrm{C} /{ }^{12} \mathrm{C}$, or ${ }^{18} \mathrm{O} /{ }^{16} \mathrm{O}$ ratio of the sample and $\mathrm{R}_{\text {standard, }}$ of the standards of Vienna Pee Dee Belemnite (VPDB) for carbon and Vienna Standard Mean Ocean Water (VSMOW) for oxygen.

Whilst samples for $\delta^{18} \mathrm{O}$ measurement were pyrolyzed to $\mathrm{CO}$ at $1,080{ }^{\circ} \mathrm{C}, \delta^{13} \mathrm{C}$ was determined by combustion under excess oxygen at a reactor temperature of $1,020^{\circ} \mathrm{C}$, with a 
precision for replicate homogenized standard material $(n>100)$ of $0.1 \%$ for $\delta^{13} \mathrm{C}$ and $0.3 \%$ for $\delta^{18} \mathrm{O}$.

Based on previous reports on the absence of significant age trends after the first 50 years of growth (Gagen et al. (2007), Young et al. (2011)), we did not detrend our stable isotope chronologies.

\subsection{Corrections for the influence of $\delta^{13} \mathrm{C}_{\mathrm{atm}}$ and atmospheric $\mathrm{CO}_{2}$ concentrations}

The $\delta^{13} \mathrm{C}$ of cellulose from KOK, AKT and MOG sites were corrected for the decline of the ${ }^{13} \mathrm{C} /{ }^{12} \mathrm{C}$ ratio of atmospheric $\mathrm{CO}_{2}$ due to release of fossil fuel and land use change, using data obtained from ice cores (Francey et al. 1999) and direct atmospheric measurements at the Mauna Loa Observatory, Hawaii http://www.esrl.noaa.gov/gmd/ccgg/globalview/co2c13/ co2c13 intro.html. The differences between each year and the pre-industrial value for $\delta^{13} \mathrm{C}$ of atmospheric $\mathrm{CO}_{2}$ and the following years were calculated and the differences were subtracted from the raw tree-ring carbon isotope series.

In a next step a pre-industrial 'pin' adjustment, taking into account the changes in the active response of trees to the increased availability of $\mathrm{CO}_{2}$ by increasing their water-use efficiency was additionally applied (McCarroll et al. 2009). The pin-adjustment result in improved correlations between climate data and carbon isotope series for MOG (heavy correction - span 0.9), KOK and AKT (span - 0.4), because the non-climatic direct $\mathrm{CO}_{2}$-effects on plant physiology are removed. For further analysis and discussions we will therefore only use the two-fold adjusted $\delta^{13} \mathrm{C}$ chronologies from all three Altai tree sites.

\section{Results and discussion}

\subsection{Tree-ring width and stable isotopes}

New standardized tree-ring width chronologies for the KOK and the AKT sites were constructed for the period 1778-2008 and 1831-2000, based on fifteen and twelve crossdated tree samples, respectively (Fig. 2a). An increasing trend in the KOK tree-ring width index chronology is visible after the 1920's, while the AKT chronology shows a slightly decreasing trend during this period (Fig. 2a). Similar decreasing tree-ring width index around 1950s was reported by Panyushkina et al. (2005), where larch suppression was explained by glacier advances lasting about 100 years in the $19^{\text {th }}$ centuries.

The MOG tree-ring index chronology built using 25 samples (Sidorova et al. 2012) shows a less pronounced increasing trend compared to the KOK site. High EPS values of 0.89-0.93 for the analyzed length of time series for all chronologies indicate a strong common signal between all trees and their suitability for dendroclimatological analyses. Despite some differences in the long-term trends among the sites, correlation analyses among the three tree-ring index chronologies revealed significant relationships $(p<0.05)$ among one another for the common period 1901-2000 (Table 1S).

For the KOK site, a $\delta^{13} \mathrm{C}$ chronology was constructed based on five individual trees that are significantly $(r=0.70-0.80 ; p<0.05)$ correlated between each other and exhibit an EPS $>0.85$ for the period 1822-2005 (Fig. 2b). Some years are missing in the chronology due to low amounts of material left after cellulose extraction for both carbon and oxygen measurements. After correcting the tree-ring $\delta^{13} \mathrm{C}$ for the changes in atmospheric $\mathrm{CO}_{2}$ the new KOK series as well as the two previously established chronologies showed slight increasing trends. The $\delta^{13} \mathrm{C}$ 

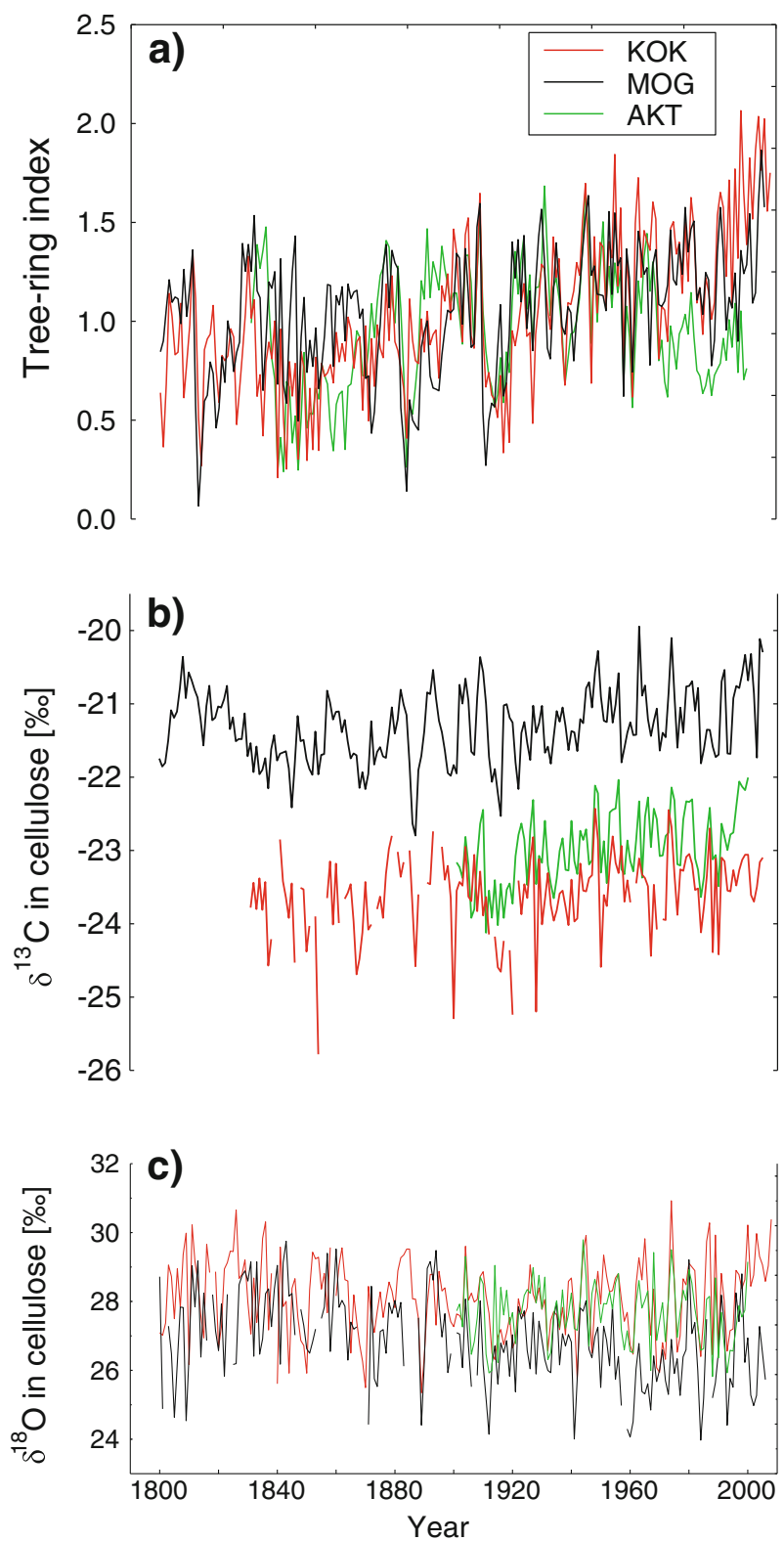

Fig. 2 Tree-ring width (a), $\delta^{13} \mathrm{C}(\mathbf{b})$ and $\delta^{18} \mathrm{O}(\mathbf{c})$ chronologies and their trend lines in comparison for $\mathrm{KOK}$, MOG, and AKT sites

chronology from the MOG site showed some dramatic changes in variations of $\delta^{13} \mathrm{C}$ values up to $2.5 \%$ from 1800 to 1801 . Moreover, $\delta^{13} \mathrm{C}$ values for the MOG chronology are $1-2 \%$ more positive compared to the other two sites along the whole record (Fig. 2b). This difference could potentially be explained by the different species and site conditions, e.g. permafrost. The $\delta^{13} \mathrm{C}$ KOK chronology agreed well with the AKT data, both in terms of the absolute values and the inter-annual variability/correlation between the sites (Table S1). 
The mean $\delta^{18} \mathrm{O}$ chronology from the KOK site (Fig. 2c) was also constructed based upon the same five individual trees used for $\delta^{13} \mathrm{C}$ and exhibited a high statistical correspondence between individual trees $(r=0.60-0.70 ; p<0.05)$ with EPS $>0.85$ for the period from 1800 to 2008. An increasing trend is observed in the $\delta^{18} \mathrm{O}$ chronology from KOK site for the recent decades, however this is not as clearly expressed as in the tree-ring width chronology (Fig. 2a). Nevertheless, the tree-ring width index and $\delta^{18} \mathrm{O}$ chronologies showed a low but significant correlation between each other $(r=0.14 ; p<0.05)$ over the last two centuries. For the period 1901-2000, the MOG and AKT chronologies showed a similar behavior and statistically significant relationships (Table. S1). The MOG and KOK $\delta^{18} \mathrm{O}$ chronologies showed increasing trends at the beginning of the 1800 's. The MOG $\delta^{18} \mathrm{O}$ chronology overall shows the strongest decreasing long-term trend of all sites (Fig. 2c). Differences in $\delta^{18} \mathrm{O}$ values from the different sites could be explained by geographical location, exposure and the availability of moisture derived from precipitation and recent melting of permafrost in the case of the MOG site. Earlier studies for the MOG site showed a thawing of the permafrost that is reflected in decreasing $\delta^{18} \mathrm{O}$ of cellulose data (Sidorova et al. 2012).

\subsection{Tree-ring width, stable isotopes and climatic parameters}

A climatological analysis between monthly temperature and monthly precipitation from September of the previous year until August of the current year with all tree-ring proxies for the MOG, KOK and AKT sites was performed (Fig. 3a-c).

Multiple regression analysis revealed a common summer temperature signal for the KOK, MOG and AKT sites, but slightly shifted in the seasonal timing for the individual proxies. For tree-ring width, temperature of June and July was found to be most important. Panyushkina et al. (2005) showed that larch trees from upper tree line of the Russian Altai indicated strong response to June and July air temperature, however this relationship was not constant over the period 1950-1991. In our study we found a strong constant relationship between tree-ring width and June-July air temperature for the period 1954-2000.

Moreover, significant relationships were detected for $\delta^{13} \mathrm{C}$ with July temperature and for $\delta^{18} \mathrm{O}$ with both August (Fig. 3a) and July temperature significant relationships were detected. All $\delta^{13} \mathrm{C}$ and $\delta^{18} \mathrm{O}$ chronologies reflected a July precipitation signal, which could not be observed for tree-ring width (Fig. 3a-c). According to geographical locations and weather station data the negative response to July precipitation for the KOK and AKT sites can be explained by a low amount of precipitation, semi-arid conditions and water shortage. The similar negative response for the MOG site could additionally be explained by the influence of the permafrost thawing depth and low water availability to the tree root system. Trees growing at high-altitude in this region are exposed to milder climatic conditions than in subarctic regions, but may still suffer from drought due to reduced water availability. Even with thawing of seasonal permafrost under increases temperature, the water is too cold to be taken up by the roots and trees are affected by water shortage in the same way as a trees growing in semi-arid conditions (Körner and Hoch 2006).

Significant relationships between $\delta^{18} \mathrm{O}$ of cellulose and May temperature for the KOK and MOG sites (Fig. 3a, b) were also found. Except for the month of June the tree-ring $\delta^{18} \mathrm{O}$ reflects significant relationships with temperature for the period from current May to August. It was also noted that the $\delta^{13} \mathrm{C}$ chronology for the KOK site responds to August temperature (Fig. 3a) as well as July, but only to July at the other sites. It likely also reflects the longer vegetation period at KOK compared with the other study sites (Fig. 3b, c)

Regarding precipitation, correlation analysis revealed a significant correlation between $\delta^{13} \mathrm{C}$ and precipitation of April for trees growing at the MOG site. This response indicates 

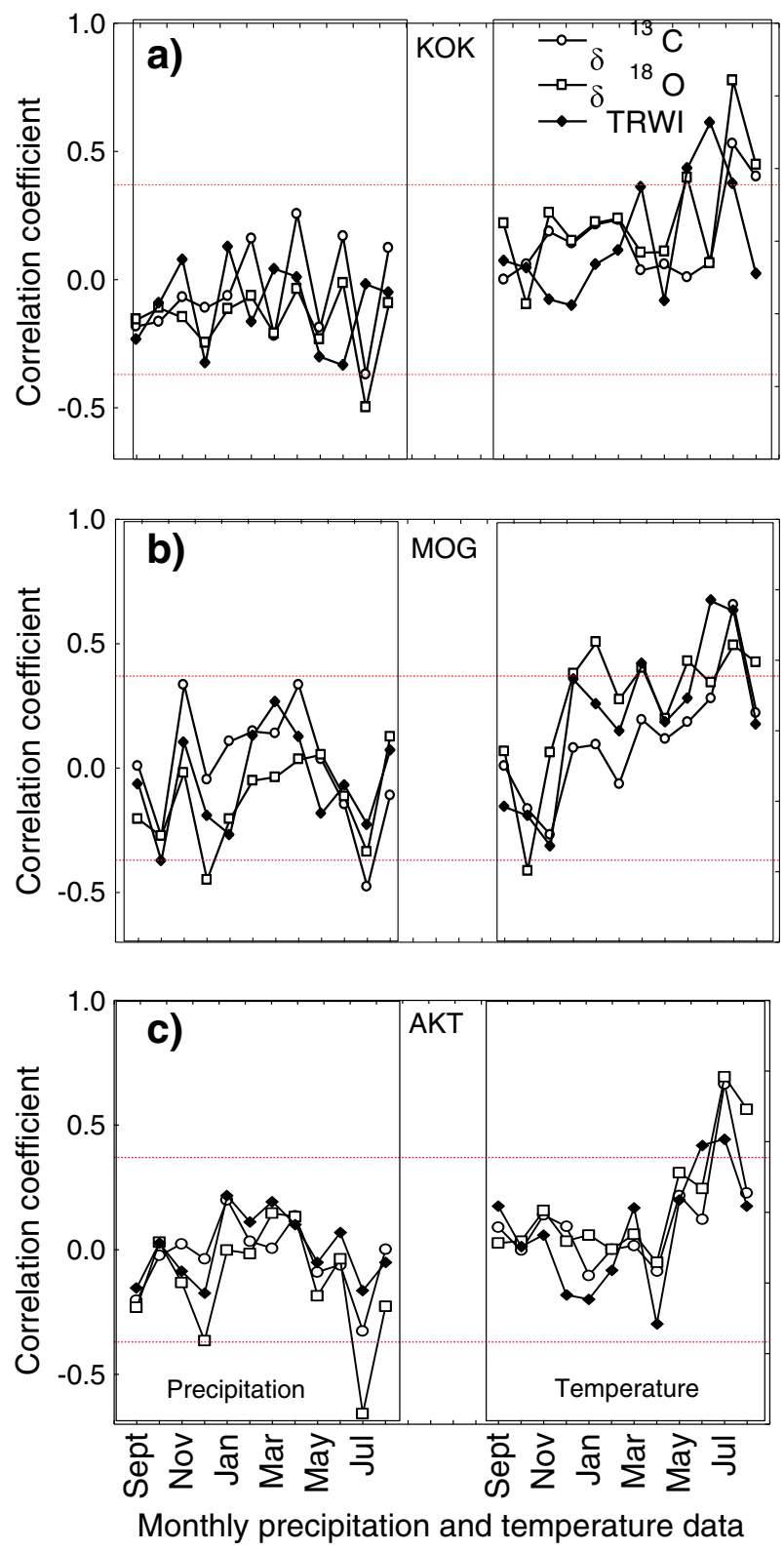

Fig. 3 Correlation coefficients between TRWI, $\delta^{13} \mathrm{C}, \delta^{18} \mathrm{O}$ chronologies and temperature (T) and precipitation (P) for the common period 1938-2000 for KOK (a), MOG (b) and AKT (c). Values above the top horizontal red line or below the bottom horizontal red line are significant at $p<0.01$

the importance of the period around snowmelt, which has shifted to earlier dates in recent decades (Vaganov et al. 1999). The main difference between tree responses to temperature recorded in $\delta^{18} \mathrm{O}$ data from MOG and the other two sites is the recording of winter and spring temperature signals. Similar findings were reported for a study conducted in northeastern Yakutia (Sidorova et al. 2008). The positive correlations of winter, spring 
temperatures and $\delta^{18} \mathrm{O}$ in cellulose could be a result of the lag between snowfall and snowmelt and the incorporation of this water by the tree into the tree-ring, where this $\delta^{18} \mathrm{O}$ signal is stored. Furthermore the influence of changes of the atmospheric circulation air masses could enhance or delay such time gaps.

Positive relationships between TRW, carbon isotopes and summer temperature are expected and explained by increasing temperature and photosynthetic activity during the growth period, which influences all parameters. Negative correlation between $\delta^{13} \mathrm{C}$ and precipitation indicates drier conditions during July.

\subsection{Spatial distribution of correlation coefficients}

Earlier studies by Adamenko (1978), Loader et al. (2010), Sidorova et al. (2012) for AKT and MOG sites showed that summer temperature is a determining tree growth factor in the Altai region. Considering the most important (summer) months for all studied sites, the spatial dimension of the correlation coefficients between tree-ring index and June-July air temperature, stable isotopes and July-August temperature, and precipitation for all available gridded data sets were calculated to visualize the patterns of a changing climate for the period 1938-2000 (Fig. S1 a-t).

Based on common signals between stable isotopes and climatic parameters for the $\mathrm{KOK}$, MOG and AKT sites the series were normalized (z-scored) to equalise the mean and variance prior to averaging (Fig. S1 a-c), $\delta^{13} \mathrm{C}$ (Fig. S1 e-g; m-o) and $\delta^{18} \mathrm{O}$ (Fig. S1 i-k; q-s) chronologies. In the results we obtained a combined tree-ring index (TRWI) (Fig. S1 d), $\delta^{13} \mathrm{C}$ (Fig. S1h; p) and $\delta^{18} \mathrm{O}$ (Fig. S11; t) chronologies, which contained even stronger temperature and precipitation signals compared to separate chronologies. Nevertheless, the summer temperature signal is well preserved in the TRWI and stable isotope data for each site separately as well as for regional chronologies. The presence of a common summer temperature signal for the $\mathrm{KOK}, \mathrm{MOG}$ and $\mathrm{AKT}$ in tree-ring width and stable isotopes provide an opportunity for a multi-parameter approach. A similar comparison based upon gridded precipitation data was less conclusive. This is because the locally distributed precipitation patterns are weakly represented by the gridded data when compared to data from local weather stations. It is well known that gridded data for such remote regions often do not adequately reflect the local conditions due to the low density of weather stations (Frank et al. 2007; Loader et al. 2010). However, according to the local weather station data we revealed a common response of stable isotope values to July precipitations. Spatial visualization of correlation coefficients revealed higher correlations to fields lying west or southwest of the tree sites, potentially indicating the source areas of air mass and moisture transport. Such information could be used to improve our knowledge about the hydrological regime in the Russian Altai.

\subsection{June-July air temperature reconstruction based on average tree-ring width chronology}

For June-July temperature, the highest correlation was obtained with TRWI only, rather than by combining TRWI with the other proxies, i.e. with the carbon or oxygen isotope ratios (Fig. S2 a). Based upon the highly significant statistical relationships observed between average June-July air temperature and TRWI chronologies from the KOK, AKT and MOG sites we combined these chronologies to a regional TRWI chronology with the goal to produce a regional June-July air temperature reconstruction for the Russian Altai.

Regression analysis was applied between combined KOK, MOG, AKT TRWI chronologies and mean June-July temperature (Table S2 a) for the calibration and verification 
periods. In all regressions $\mathrm{K}_{\mathrm{s}}$ is significant $(p<0.01)$ (see Table $\mathrm{S} 2$ a-c) based on the null hypothesis test $\left(K_{\mathrm{s}}=0\right)$ and binomial distribution $\mathrm{B}(\mathrm{N}, 1 / 2)$. The t-value for the regression coefficients (slope) shows that the coefficients are significantly different from zero ( $p=$ 0.0000). Based upon these statistics our models are adequate for climate reconstructions.

Moreover, statistical analysis between residuals chronologies showed high significant and constant relationships for the same periods, which were considered for the multiple regression analysis additionally (data not shown).

To assess the regional relevance of the June-July air temperature reconstruction and to check for regional differences, the data were correlated with instrumental records from the different weather stations available across the region (Table S3). This analysis showed consistently moderate, significant correlation coefficients for all stations $(r=0.51-0.74 ; p<0.05)$, expect for the one at Barnaul $(r=0.34 ; p<0.05)$, which may reflect the distant location of this station and the relatively lower elevation of this location compared to the tree-ring sites. The results show that despite gaps in the meteorological data and relatively short records, our analysis does not depend on a fortuitous correlation to just one location, but represents a regional signal.

According to Kotlyakov (2006) the average air temperature along an altitude gradient is increasing by $0.6^{\circ} \mathrm{C}$ for each $100 \mathrm{~m}$ of altitude. Myglan et al. (2012) showed that the average air temperature between weather station data located originating from the valley and at highaltitude could differ up to $10^{\circ} \mathrm{C}$. We assume an average June-July air temperature of $21.05^{\circ} \mathrm{C}$ according to the Chinese Altai weather station data located at $737 \mathrm{~m}$ asl for the period from 1954 to 2000 . Based on this we estimate that at an altitude of $2,400 \mathrm{~m}$ the temperature is around $11.07^{\circ} \mathrm{C}$ or $11.05^{\circ} \mathrm{C}$, respectively, when using two approaches from the literature (Kotlyakov 2006; Myglan et al. 2012). According to these approaches our reconstructed June-July air temperature data most likely need to be adjusted by minus $11.6^{\circ} \mathrm{C}$. The same procedure will be applicable for the July-August temperature reconstruction based on stable isotopes.

Accordingly, a 205-year June-July air temperature reconstruction based on tree-ring width was developed for the Russian Altai (Fig. 4a). The chronology shows rapid temperature increases after the 1980's with the maximum value in 2004 (Fig. 4a), this trend is similar to those identified in ice cores (Eichler et al. 2009) and lake sediments (Kalugin et al. 2007). The difference between the weather stations and the reconstructed data (Fig. 4d) could reflect the quality of the temperature data and relative location of the weather station, as well as differences in the quality/response of the proxy data.

\subsection{July-August temperature reconstruction based on combination of carbon and oxygen isotope chronologies}

Testing correlation coefficients between different combinations of proxies with July-August temperature showed the best relationship with the average normalized $\delta^{13} \mathrm{C}$ and $\delta^{18} \mathrm{O}$ in cellulose chronologies $(\mathrm{C}+\mathrm{O})$ (Fig. $\mathrm{S} 2 \mathrm{~b}$ ). Both carbon and oxygen remained highly significant in the multiple regression model after applying autocorrelation analyses. Thus, a regression equation was calculated for the calibration period (Table S2 b), and July-August temperature was reconstructed for the period 1800-2005 (Fig. 4b) and compared with instrumental weather station data (Fig. 4e).

Our reconstruction indicates that the maximum temperatures values were recorded in 1811 and 1818. According to historical documents (Zadonina and Levi 2008) these years were indeed characterized by exceptionally hot summers with crop failure and starvation. Similar findings were reported by Panyushkina et al. (2005) for the tree-ring width chronology constructed for the upper tree line in the Russian Altai. The lowest values in 1869 and 1870 agree with reported cold weather conditions and frost anomalies during the summer. 

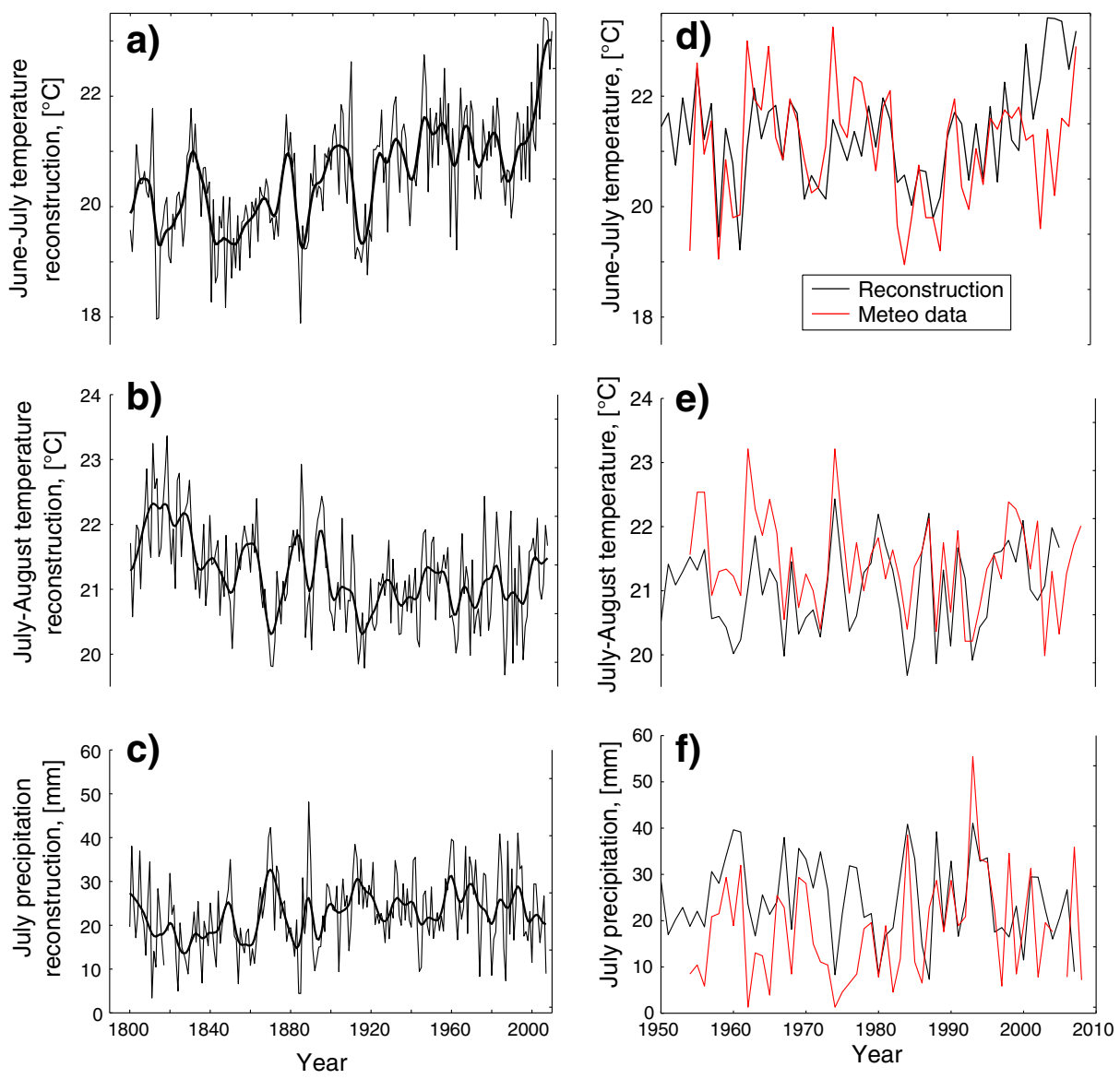

Fig. 4 Annual and smoothed (11-year Hamming window) temperature reconstructions for June-July (a) and July-August (b) inferred from TRWI and combined $\delta^{13} \mathrm{C}$ and $\delta^{18} \mathrm{O}$ chronologies, respectively, and July precipitation reconstruction obtained from $\delta^{18} \mathrm{O}$ chronology (c). Correspondence between instrumental data and reconstructions are shown on the graphs (d-f)

According to the Chinese Altai weather station data the minimum temperature was recorded in the summer 1984. In general, the period from 1984 to 1997 is characterized as "dry". During this period the amount of spring and summer precipitation was only half that of the long-term mean. Consequently, decreasing tree-ring widths from 1984 to 1997 could be explained by summer drought that could also partly explain the difference between treering proxies and weather station data.

\subsection{July precipitation reconstruction based on oxygen isotopes}

We found that the precipitation signal was best recorded in the oxygen isotope chronology (Fig. $\mathrm{S} 1 \mathrm{c})$, rather than in any combination of proxies. Calibration and verification models were computed (Table S2 c). The July precipitation reconstruction (Fig. 4c) was correlated with other nearby data from nearby high-altitude weather station data (Table S3) to explore the spatial distribution of precipitation signals recorded in the Altai-Sayan stable isotope chronology. The 
meteorological data from the Barnaul weather station, whilst currently the longest available, are unfortunately not applicable for the development of reconstructed precipitations from our dataset due to the station's low elevation and its proximity to Barnaul city. Nevertheless, a common precipitation signal is captured by trees from high-altitude sites growing at 2,000 m asl. A significant response was also found between precipitation reconstruction and precipitation data from other weather stations located at high elevations within $800 \mathrm{~km}$ (Table S3). However, differences between low and high elevations should be taken into account. Precipitation increases around $10 \mathrm{~mm}$ per $100 \mathrm{~m}$ elevation (Kotlyakov 2006).

In the reconstruction (Fig. 4) we observed the lowest amount of precipitation in the years $1811,1824,1884$, and $1885(-2 \sigma)$. For example, the year 1884 is characterized as a dry and hot according to June-July and July-August temperature reconstructions (Fig. 4). According to historical documents recorded by the local inhabitants a very dry summer event was indeed recorded in 1811 and 1884, and characterized as unfavorable for farming and agriculture (Zadonina and Levi 2008).

According to our precipitation reconstruction, extremely high amount of precipitation $(+3 \sigma)$ was recorded in the year 1889 (Fig. 4b), which caused decreasing summer temperature (Fig. 4a, c). Reconstructed data agree well with instrumental data (Fig. 4f).

Regionally representative precipitation reconstructions are difficult to develop for the entire Altai-Sayan Mountain region due to the complex topography and climatology of the Mountains (Magda et al. 2011) and the scarcity of reliable weather stations. Our precipitation reconstruction is therefore the first of its kind obtained for the Russian Altai and although only composed of three representative sites, it may serve to improve our knowledge of extreme dry $(-2 \sigma) 1811,1824,1884$ and wet (from $+3 \sigma$ to $+2 \sigma) 1889$, 1984 events. Such an interpretation would not have been possible using tree-ring width data alone.

\section{Conclusions}

A regionally relevant, multi-site, multi-parameter tree-ring study was conducted to develop a series of regional palaeoclimate composites using physical and chemical indicators in absolutely dated tree-rings. The series were correlated directly against instrumental meteorological observations and the seasons of highest correlation identified and interpreted in relation to the climate and the physiology of the trees growing in the Altai region. Findings are summarized as follows

1. The temperature variability during the growing season (June-August) and the frequency of observed drought events $(1811,1824$, and 1884) in the Russian Altai appear to be well recorded in tree-ring width and stable isotope chronologies.

2. The temperature signal preserved in the trees is strongly recorded at local and regional scales for all studied sites indicating large-scale coherency. This enables the reconstruction of June-July and July-August temperatures for the last 200 years using tree-rings and stable isotopes.

3. The July precipitation signal recorded in tree-ring stable isotopes from the KOK, MOG and AKT sites express differently in their spatial patterns, but nevertheless demonstrate a close agreement with local weather station measurements. This indicates that local precipitation data are of good quality.

4. This study provides the first July precipitation reconstruction in the Russian Altai based on oxygen isotopic variability recorded in tree-rings. Although not a direct proxy for 
precipitation, indirect associations with temperature, air-mass (source) and amount effects provide information that can potentially improve the understanding of hydrological changes and the occurrence of extreme events in the Russian Altai.

5. In exploring the potential for multi-parameter research in this region, a new June-July and July-August temperature reconstruction inferred from tree-ring width and $\delta^{13} \mathrm{C}$ data as well as a July precipitation reconstruction obtained from $\delta^{18} \mathrm{O}$ data serve to highlight the importance of a multi-proxy approach to dendroclimatology. More comprehensive temperature and precipitation reconstructions in time and space could benefit from including other archives such as ice cores and lake sediments for the Russian Altai.

Acknowledgements The work was supported by Marie Curie IIF (EU-ISOTREC 235122) awarded to Olga Sidorova, SNSF 200021_121838/1, and SNSF - SCOPES Iz73z0-128035/1, MK-1675.2011.6, Russian Scientific School 5327.2012.4 and RFBR grant 13-05-00620. Neil J. Loader thanks the UK NERC (NE/ B501504) and C3W for support. We thank Eugene Vaganov for the suggestions in the manuscript and five reviewers for their constructive and helpful comments.

\section{References}

Adamenko MF (1978) 'Dynamics of larch tree growth as indicator of thermical regimes of summer in the Altai Mountain. Regional geographical investigations in the Western Siberia', Nauka, Novosibirsk, pp. 20-23.

Cook ER, Kairiukstis LA (1990) Methods of Dendrochronology. Applications in the environmental sciences. Kluwer Acad. Publ, Dordrecht, Dordrecht, p 394

Cook ER, Krusic PJ (2008) 'A Tree-Ring Standardization Program Based on Detrending and Autoregressive Time Series Modeling, with Interactive Graphics (ARSTAN)', in Cook, E.R. and Krusic, P.J. (eds.).

Craig H (1961) Isotopic variations in meteoric waters. Science 133:1702-1703

Dansgaard W (1964) Stable isotopes in precipitation. Tellus 16:436-468

Draper NR, Smith H (1966) Applied regression analysis, p. 407.

Durbin J, Watson GS (1951) Testing for serial correlation in least squares regression I. Biometrika 37:409-428

Eichler A, Oliver S, Henderson K, Laube A, Beer J, Papina T, Gäggeler HW, Schwikowski M (2009) 'Temperature response in the Altai region lags solar forcing', Geophys Res Lett.

Francey RJ, Allison CE, Etheridge DM (1999) A 1000-year high precision record of $\delta^{13} \mathrm{C}$ in atmospheric $\mathrm{CO}_{2}$. Tellus 51:170-193

Frank D, Ovchinnikov DV, Kirdyanov AV, Esper J (2007) 'The potential for long-term climatic reconstruction in the Central Altay mountains from living and relict larch', In TRACE Tree Rings in Archaeology, Climatology and Ecology. Proceedings of the Dendrosymposium 2006:85-96

Fritts HC (1976) Tree-rings and climate. Acad. Press, London, p. 567

Gagen MH, McCarroll D, Loader NJ, Robertson I, Jalkanen R (2007) Exorcising the 'segment length curse' summer temperature reconstruction since AD 1640 using non de-trend stable carbon isotope ratios from line trees in northern Finland. The Holocene 17:433-444

Hettmansperger T (1984) Statistical Inference Based on Ranks. Wiley \& Sons, Incorporated, John, p 323

Kalugin I, Daryin A, Smolyaninova L, Andreev A, Diekmann B, Khlystov O (2007) 800-year-long records of annual air temperature and precipitation over southern Siberia inferred from Teletskoye lake sediments. Quaternary Research 67:400-410

Körner C, Hoch G (2006) A test of treeline theory on a montane permafrost island. Arctic Antarctic and Alpine Research 38:113-119

Kotlyakov VM (ed) (2006) Iced northern and central Eurasia in the modern epoch. Nauka, Novosibirsk, p 482

Leavitt SW (2010) 'Tree-ring C-H-O isotope variability and sampling', Sci Total Environ, 5244-5253.

Loader NJ, Robertson I, Barker AC, Switsur VR, Waterhouse JS (1997) Improved technique for the batch processing of small whole wood samples to alpha-cellulose. Chemical Geology 136:313-317 
Loader NJ, Helle G, Los S, Lehmkuhl F, Schleser GH (2010) Twentieth-century summer temperature variability in the southern Altai Mountains: A carbon and oxygen isotope study of tree-rings. The Holocene 20:1149-1156

Magda VN, Block J, Oidupaa OC, Vaganov EA (2011) Extraction of the climatic signal for moisture from tree-ring chronologies of Altai-Sayan mountain forest-steppes. Contemporary Problems of Ecology 4:716-724

McCarroll D, Loader NJ (2004) Stable isotopes in tree rings. Quaternary Science Review 23:771-801

McCarroll D, Gagen MH, Loader NJ, Robertson I, Anchukaitis KJ, Los S, Young G, Jalkanen R, Kirchhefer A, Waterhouse JS (2009) Correction of tree-ring stable carbon isotope chronologies for changes in the carbon dioxide content of the atmosphere. Geochimica et Cosmochimica Acta 73:1539-1547

Mitchell TD, Jones PD (2005) An improved method of constructing a database of monthly climate observations and associated high-resolution grids. Int J Climatology 25:693-712

Myglan VS, Ovchinnikov DV, Vaganov EA, Bykov NI, Gerasimova OV, Sidorova OV, Silkin PP (2009) Construction of 1772-year tree-ring width chronology for Altai Republic. Izvestiya RAN serija geograficheskaja 6:70-77 (in Russian)

Myglan VS, Oidupaa OC, Vaganov EA (2012) Construction of 2367-year tree-ring width chronology for the Altay_Sayan region. Archeology, etnography and antropology of Eurasia 51:76-83

Ovchinnikov DV, Panyushkina IP, Adamenko MF (2002) Millennial tree-ring chronology of larch from the Altai Mountain and application for temperature reconstruction. Geography and natural resources 1:102108

Panyushkina IP, Ovchinnikov DV, Adamenko MF (2005) Mixed response of decadal variability in larch treering chronologies from upper tree-lines of the Russian Altai. Tree-Ring Research 61:33-42

Schweingruber FH (1996) Tree rings and environment dendroecology. Paul Haupt Publ Bern, Stuttgart, Vienna, p. 609

Sidorova OV, Siegwolf RTW, Saurer M, Naurzbaev MM, Vaganov EA (2008) Isotopic composition $\left(\delta^{13} \mathrm{C}\right.$, $\delta^{18} \mathrm{O}$ ) in Siberian tree-ring chronology. Geophysical research Biogeosciences 113:1-13

Sidorova OV, Saurer M, Myglan VS, Eichler A, Schwikowski M, Kirdyanov AV, Bryukhanova MV, Gerasimova OV, Kalugin I, Daryin A, Siegwolf RTW (2012) A multi-proxy approach for revealing recent climatic changes in the Russian Altai. Climate Dynamics 38:175-188

Vaganov EA, Hughes MK, Kirdyanov AV, Schweingruber F, Silkin PP (1999) Influence of snowfall and melt timing on tree growth in Subarctic Eurasia. Nature 400:149-151

Wigley T, Briffa K, Jones P (1984) On the average value of correlated time series, with application in dendroclimatology and hydrometeorology. J Clim Appl Met 23:201-213

Young GHF, Demmler JC, Gunnarson BE, Kirchhefer AJ, Loader NJ, McCarroll D (2011) 'Age trends in tree ring growth and isotopic archives: A case study of Pinus sylvestris L. from northwestern Norway', Global Biogeochemical Cycles 25, doi:10.1029/2010GB003913

Zadonina IV, Levi KG (2008) Chronology of natural and social fenomens in Siberia and Mongolia Irkutsk State University, Irkutsk, p. 759. 